\title{
Moodle-Based Learning: Motivating and Demotivating Factors
}

\author{
https://doi.org/10.3991/ijet.v15i02.11297
}

Tatiana Yu. Aikina, Liudmila M. Bolsunovskaya ${ }^{(\varpi)}$

National Research Tomsk Polytechnic University, Tomsk, Russia

bolsunovskaya@inbox.ru

\begin{abstract}
Over the past 10 years, a lot of universities worldwide have designed different online courses available to their students. The emergence of online courses makes Higher Education a more flexible and elastic concept. The present paper documents a qualitative study that examines motivating and demotivating factors in using Moodle for English language learning in higher schools. The survey encompasses data collected from 137 students and 20 teachers in a higher technical school (Russia) with the focus on students' and teachers' perception of Moodle-based learning. Analysis of the obtained data reveals a set of factors concerning pedagogical, technical, management approaches towards Moodle implementation. The results suggest further development of positive experiences and minimizing demotivating factors in online learning environment.
\end{abstract}

Keywords-Moodle, collaborative learning, English language learning, elearning, innovative approach

\section{Introduction}

The first version of Moodle (or the modular object-oriented dynamic learning environment) was written and designed by Martin Dougiamas, who has graduate degrees in computer science and education. Due to this background, he developed a tool, which meets technological and pedagogical requirements [1]. The Moodle platform has proved to be an effective learning tool as it is interactive, introduces multi-media content, and provides broad opportunities to collaborate, follow guidance, give and receive feedback, as well as reinforce prior learning material. Its core principle is storing, tracking, and measuring learning and providing an environment for learning communities.

Before on-line courses were incorporated into everyday learning at universities, students, as a rule, were not engaged into collaborative learning outside the classroom. Nowadays, with Moodle as one of the most effective learning management systems, this problem is no longer urgent, although the issue of motivating active participation is still on the agenda. Since the discussed electronic platform is a renewable education environment, various changes can be made to promote both teachers' and learners' motivation. It is worth mentioning that when given a choice of 
online language learning outside the class, students are free to select any suitable internet resource that is user-friendly and meets their needs. Consequently, it is our concern to make the work on Moodle their preferable choice.

\section{$2 \quad$ Literature Review}

Incorporating Moodle is an essential issue in the research field of web-based curricula [2], as it is widely adopted both by schools and universities [3, 4]. Previous studies have indicated positive influence of applying Moodle in learning on students' learning performance, sense of community, comfort in the online classroom and on their self-awareness [5].

Theoretical analyses of literature review showed that integration of digital technologies into the university curricula and educational process helps to increase the level of students' motivation, develop their digital competence, enhance academic performance in basic subjects and collaborative work, achieve better text writing skills, learning outcomes, learning interest, creativity, and learning strategies [6]. In particular, Moodle usually allows course management, educational support, generation and distribution of content to students as well as an interaction between all involved parties (students, teachers, monitors, coordination and support) [7]. The experimental results [8] have proved that the introduction of new online technologies through a specialized e-learning platform leads to significant improvements of the overall performance of students.

Ayan E. suggests that the level of students' motivation depends on the content of the online course addressing their interests [9]. According to Mayer R.E., effective motivational features include adding appealing graphics or challenging scenarios that do not distract the learner from essential processing [10].

Ayan E. has also pointed out teacher-focused, institution-focused and learnerfocused challenges in applying Moodle in teaching English, namely: creating supporting contents and management, trial and error processes, preparing appropriate online materials intended for non-homogeneous classes, preventing plagiarism, need for a grading system.

Sanchez R.A., Hueros A.D. [11] have investigated factors that incentify students to use the Moodle virtual teaching system and come to a conclusion that technical support has a direct effect on the perceived ease of use and perceived usefulness. Their research has revealed the necessity for recruiting personnel trained in the use of distance learning systems in order to support the teaching staff and students, and boost their motivation to use the learning systems. With a view to help lecturers as "digital immigrants" to overcome the difficulties they face with electronic environment implementations, Goh, W. et al. have considered their perception of teaching via Moodle [12].

Reinders $\mathrm{H}$. and Beson $\mathrm{Ph}$. highlight that within technology-enhanced learning students can derive motivation and effective support from other learners and find opportunities for language learning interaction in meaningful context [13]. 


\section{$3 \quad$ Materials and Methods}

The present study was conducted at National Research Tomsk Polytechnic University, Russia. It engaged 137 first- and second-year students doing their Bachelor's and Specialist's degrees in Engineering, as well as twenty lecturers. The aim of the study was to examine factors that affect students' and educators' motivation and demotivation in using the university online learning environment.

The survey consisted of four questionnaires, each comprising both multiple answer and open-ended questions (see Appendix). The participants based their responses on their in-class and out-of-class experience of learning and teaching through the use of the university learning management system (LMS), Moodle. The findings demonstrate the respondents' perception of e-learning as well as the obstacles they experienced in the process.

\section{$4 \quad$ Results and Discussion}

According to the data collected from junior students, the overwhelming majority of them - $126(92 \%)$ - agreed on the fact that an opportunity to get extra points to their attestation encourage them to use Moodle. Ninety-nine respondents (72\%) consider mobile and laptop access to the Moodle platform as a motivating factor to apply it for learning. The survey results also indicate that receiving feedback from the teacher via Moodle increases the learners' motivation as evidenced by 82 students $(60 \%) .81$ pollees $(59 \%)$ reported that their motivation is also based on the way the online learning material is organised. Opportunity for collaborative learning was regarded as motivating by 41 respondents (30\%). These results are shown in Fig.1.

Apart from those suggested, the following positive factors have typically been mentioned in the students' responses: the opportunity to revise the learning material and retake tests, a large amount of additional information for self-study.

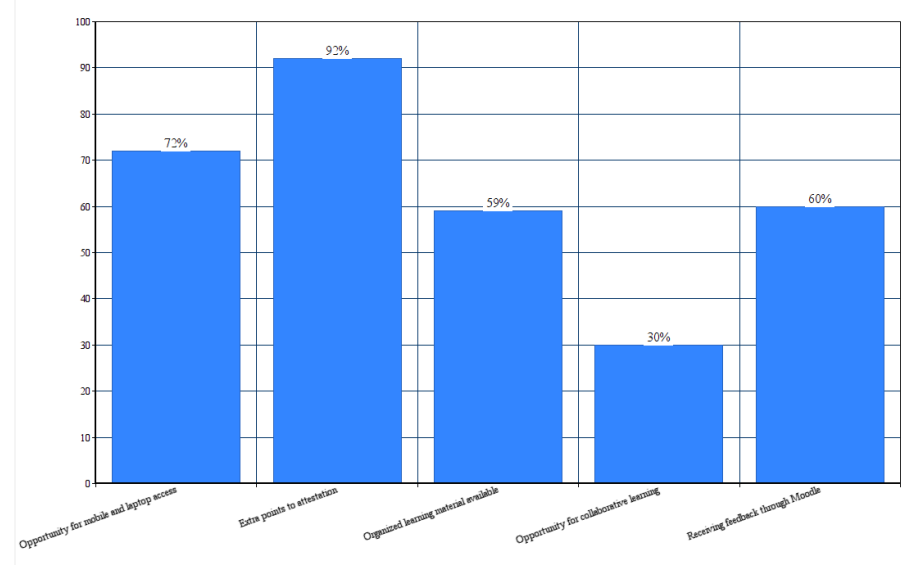

Fig. 1. Motivating factors for using Moodle: students' perception 
Data presented in Fig. 2 reveal demotivating factors that affect student's participation in online learning via Moodle. Technical problems encountered while working with the electronic platform were considered the most demotivating factor: 113 learners $(82 \%)$ reported about technical difficulties, among them: problems with Internet access, uploading and downloading documents on mobile, system failures. Additional workload was considered the second-most demotivating aspect: 62 respondents (45\%) agreed that fulfilling assignments in the online learning environment adds to their time spent on studying a subject. About one-third of the students surveyed - $45(33 \%)$ - feel that the volume of assignments demotivate them. Meanwhile, only 23 of them (17\%) were discouraged by the level of assignments.

Besides, among factors negatively affecting student's motivation for using Moodle in learning, the following aspects have been frequently mentioned in the comments: set deadlines, misprints in the tests, incorrect automatic evaluation (due to a large number of possible correct answers in fill-in activities).

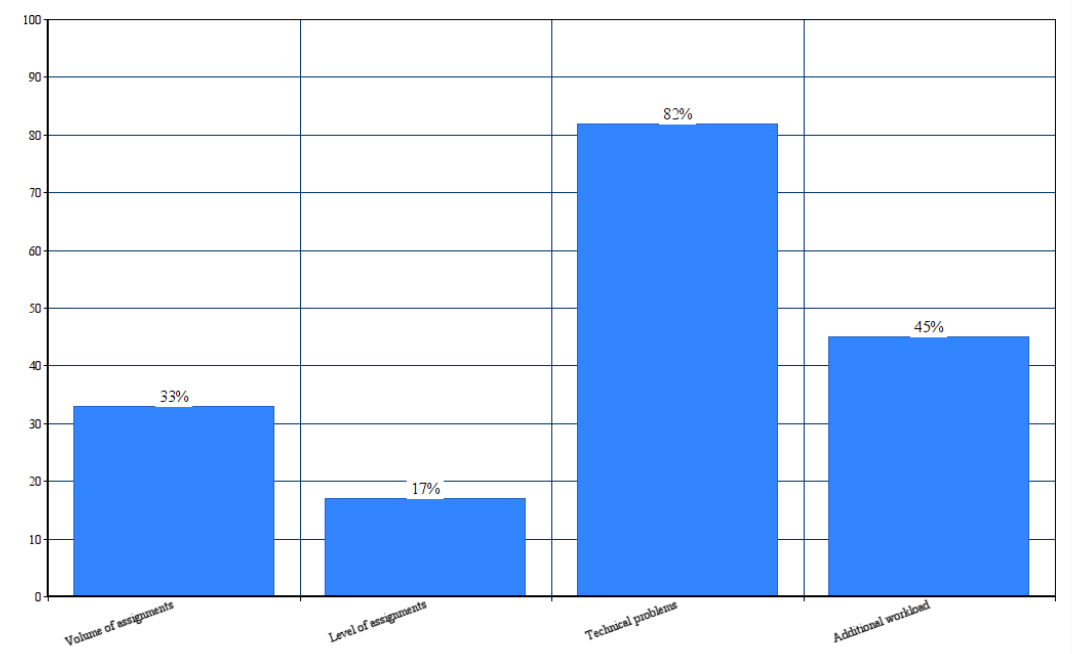

Fig. 2. Demotivating factors for using Moodle: students' perception

In regard to the academic staff, data analysis has shown that equally powerful factors that increase their motivation for using Moodle are automatic checking of tests and an opportunity to post news and additional learning materials as identified by 17 respondents out of $20(85 \%)$. The opportunity to set individual assignments is also considered a motivating feature for implementing Moodle into the education process since it was mentioned by 14 university lecturers $(70 \%)$. A large number of educators -13 respondents $(65 \%)$ - appreciated the opportunity to organize collaborative learning online. According to 12 respondents $(60 \%)$ analytics for monitoring student behavior in Moodle increases their motivation. Half of the teachers $(50 \%)$ perceive extra payments for using Moodle in their workplace as a motivating factor for its application. 9 respondents $(45 \%)$ admitted that cost-time efficiency of the teaching 
and learning process encourages them to employ the Moodle platform. This statistic is shown in Fig. 3.

According to the comments on open-ended questions, the university lecturers surveyed most frequently identified the following benefits gained from using Moodle: learning and teaching autonomy, interactivity, the storage function for both learning resources and students' papers, saving classroom time, lack of necessity to print out learning materials, the opportunity to modify the electronic course to meet learners' individual needs and learning objectives.

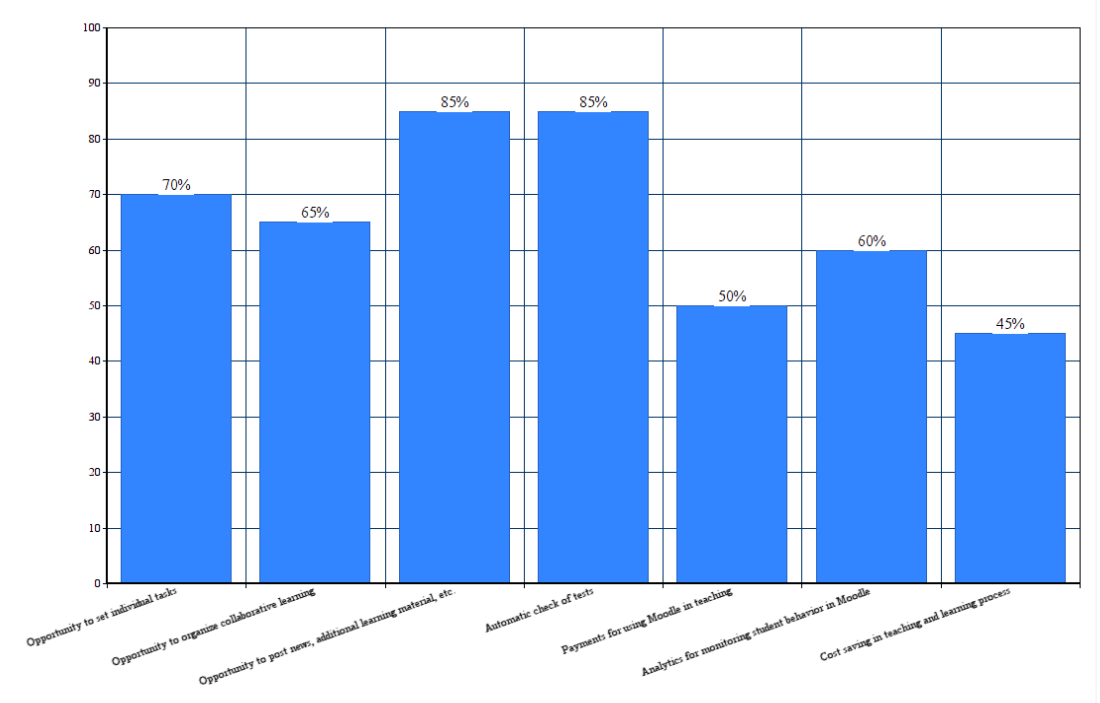

Fig. 3. Motivating factors for using Moodle: teachers' perception

As it can be seen from Fig. 4, additional workload due to Moodle implementation and technical problems accompanying it are the main factors to decrease lecturers' motivation as evidenced by 14 respondents $(70 \%)$. Fewer pollees - $11(55 \%)-$ considered plagiarism in students' works uploaded via Moodle as demotivating. The same number of lecturers highlighted difficulty in identifying the actual user in assessment of knowledge as a possible destructor.

The survey results and comments from the respondents suggest that the most common obstacles for the academic staff relate to technical and organizational problems: lack of technical support from the university, students' failing to meet deadlines, some students' reluctance to work online. 


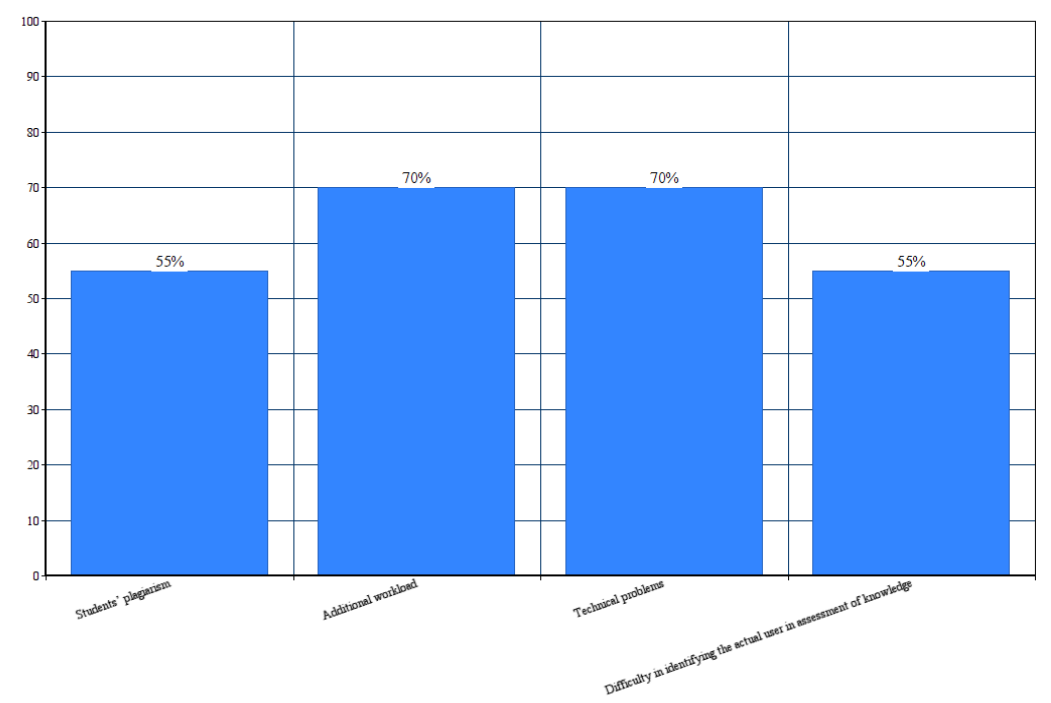

Fig. 4. Demotivating factors for using Moodle: teachers' perception

\section{Conclusion}

The objective behind conducting this study was to investigate the problem of motivation and demotivation for learning and teaching in the Moodle environment.

The findings reported in this study clearly indicate the key factors that facilitate students' motivation to apply Moodle for learning are: extra points to students' attestation, opportunities for mobile and laptop access, receiving feedback from the teacher via Moodle and organized learning material available online. Besides, the obtained data suggest that the most demotivating factors that affect students' participation in online learning via Moodle are: technical problems, set deadlines, misprints in the tests and incorrect automatic evaluation.

The conclusion drawn from the data collected from university lecturers is that the most powerful factors that increase their motivation in teaching via Moodle are: automatic checking of tests, the opportunities to post news and additional learning materials, set individual assignments, organize collaborative learning online, and have analytics for monitoring student behavior in Moodle. Meanwhile, from the lecturers' responses it is clear that the main demotivating factors for implementing Moodle are: additional workload, technical problems, plagiarism in students' works, and difficulty in identifying the actual user in assessment of knowledge.

Considering all the points under discussion, the following improvements can be suggested in order to organize the learning process more effectively. Firstly, since there is a significant demand for constant technical support, Moodle administrators and course creators should work in close coordination with those teachers who update electronic courses and implement them to support their face-to-face teaching. Various ways of instructions for teachers in the form of webinars, seminars, workshops, 
written instructions, etc. should be provided on a regular basis. Possible problems can be prevented by testing every new course for mistakes and misprints in focus-groups. Secondly, students should be engaged in the discussion of rules for teacher-student and student-student collaboration in Moodle, for instance, reasonable deadlines for submitting their essays, time for providing feedback, the amount of assignments to be uploaded online. Thirdly, measures should be taken to prevent plagiarism in students' works as well as to identify the real user of the electronic platform. This can be achieved by setting a transparent grading system including grades for the level of originality, meeting deadlines, as well as confirming the knowledge in class.

The obtained results need to be taken into consideration by teachers, administrators and technical support in order to create motivational conditions for both learners and teachers in the Moodle environment.

\section{Acknowledgement}

The research is carried out at Tomsk Polytechnic University within the framework of Tomsk Polytechnic University Competitiveness Enhancement Program grant.

\section{$7 \quad$ References}

[1] Dougiamas, M. and Taylor, P.C. (2003) Moodle: Using Learning Communities to Create an Open Source Course Management System. Proceedings of the EDMEDIA 2003 Conference, Honolulu, Hawaii.

[2] Badia, A. (2015). Research trends in technology-enhanced learning. Infancia y Aprendizaje, 38(2), 253-278. https://doi.org/10.1080/02103702.2015.1016744

[3] De Smet, C., Bourgonjon, J., De Wever, B., Schellens, T., \& Valcke, M. (2012). Researching Instructional Use and the Technology Acceptation of Learning Management Systems by Secondary School Teachers. Computers and Education, 58(2), 688-696. https ://doi.org/10.1016/j.compedu.2011.09.013

[4] Pynoo, B., Devolder, P., Tondeur, J., Van Braak, J., Duyck, W., \& Duyck, P. (2011). Predicting Secondary School Teachers' Acceptance and Use of a Digital Learning Environment: A Cross-sectional Study. Computers in Human Behavior, 27(1), 568- 575. https://doi.org/10.1016/j.chb.2010.10.005

[5] Sayekti, R. (2018) The Implementation of E-learning System at UIN Sumatera Utara in Response to Technology Challenge in Education. Journal of Physics: Conference Series: 970 (1). https://doi.org/10.1088/1742-6596/970/1/012026

[6] Badia, A., Martín D., Gómez M. (2018). Teachers' Perceptions of the Use of Moodle Activities and Their Learning Impact in Secondary Education.

[7] Viegas, C., Marques, A., Alves, G. R., Lobo, A., Costa-Lobo C. (2012) Engaging Students by Moodleing a Course? Case Studies at the Polytechnic of Porto - School of Engineering. International Journal of Engineering Pedagogy, 2 (3), 40. https://doi.org/10.3991/ijep.v2i3. $\underline{2154}$

[8] Bouroumi, A., Fajr, R. (2014) Collaborative and Cooperative E-learning in Higher Education in Morocco: A Case Study, International Journal of Emerging Technologies in Learning, 9 (1), 66-72. https://doi.org/10.3991/ijet.v9i1.3065 
[9] Ayan, E. (2015) Moodle as Builder of Motivation and Autonomy in English Courses. Open Journal of Modern Linguistics, 5, 6-20. https://doi.org/10.4236/ojml.2015.51002

[10] Mayer, R.E. (2014) Incorporating Motivation into Multimedia Learning. Learning and Instruction, 29, 171-173. https://doi.org/10.1016/j.learninstruc.2013.04.003

[11] Sanchez, R.A., Hueros, A.D. (2010) Motivating Factors that Influence the Acceptance of Moodle Using TAM. Computers in Human Behavior 26, 1632-1640. https://doi.org/10.10 16/j.chb.2010.06.011

[12] Goh, W. W., Hong, J. L., Gunawan, W. (2014) Exploring Lecturers' Perceptions of Learning Management System: An Empirical Study Based on TAM. International Journal of Engineering Pedagogy, 4 (3), 48-54. https://doi.org/10.3991/ijep.v4i3.3497

[13] Reinders, H., Beson, Ph. (2017) Research agenda: Language Learning Beyond the classroom. Language Teaching.

\section{Authors}

Tatiana Yu. Aikina is an associate professor at the Division for Foreign Languages, National Research Tomsk Polytechnic University (Lenin Ave, 30, 634050, Tomsk, Russia).

Liudmila M. Bolsunovskaya is an associate professor at the Division for Foreign Languages, National Research Tomsk Polytechnic University (Lenin Ave, 30, 634050, Tomsk, Russia).

Article submitted 2019-07-15. Resubmitted 2019-08-29. Final acceptance 2019-09-21. Final version published as submitted by the authors. 


\section{$9 \quad$ Appendix}

\subsection{Motivating factors for using Moodle}

Table 1. Student Questionnaire 1

\begin{tabular}{|l|l|l|}
\hline \multicolumn{1}{|c|}{$\begin{array}{c}\text { What factors motivate you to apply Moodle in your learning? } \\
\text { (tick as many as apply) }\end{array}$} & Tick \\
\hline & \multicolumn{1}{|c|}{ Opportunity for mobile and laptop access } & \\
\hline & Extra points to attestation & \\
\hline & The way the online learning material is organised & \\
\hline & Opportunity for collaborative learning & \\
\hline & Receiving feedback through Moodle & \\
\hline & & \\
\hline & & \\
\hline & & \\
\hline & & \\
\hline
\end{tabular}

Table 2. Student Questionnaire 2

\begin{tabular}{|l|l|l|}
\hline & \multicolumn{1}{|c|}{$\begin{array}{c}\text { What factors demotivate you to apply Moodle in your learning? (tick as many as } \\
\text { apply) }\end{array}$} & Tick \\
\hline & Volume of assignments & \\
\hline & Level of assignments & \\
\hline & Technical problems & \\
\hline & Additional workload & \\
\hline
\end{tabular}

What is the main benefit you have gained from using Moodle?

What obstacles have you faced while using Moodle?

Table 3. Teacher Questionnaire 1

\begin{tabular}{|l|l|l|}
\hline & \multicolumn{1}{|c|}{\begin{tabular}{c}
\multicolumn{1}{|c|}{ What factors motivate you to apply Moodle in your teaching? } \\
(tick as many as apply)
\end{tabular}} & Tick \\
\hline & Opportunity to set individual assignments & \\
\hline & Opportunity to organize collaborative learning & \\
\hline & Opportunity to post news, additional learning material, etc. & \\
\hline & Automatic check of tests & \\
\hline & Payments for using Moodle in teaching & \\
\hline & $\begin{array}{l}\text { Analytics for monitoring student behavior in Moodle (page views, last logged, most } \\
\text { visited day) }\end{array}$ & \\
\hline & Cost saving in teaching and learning process & \\
\hline
\end{tabular}


Table 4. Teacher Questionnaire 2

\begin{tabular}{|l|l|l|}
\hline & $\begin{array}{l}\text { What factors demotivate you to apply Moodle in your teaching? (tick as many as } \\
\text { apply) }\end{array}$ & Tick \\
\hline & \multicolumn{1}{|c|}{ Students' plagiarism } & \\
\hline & Additional workload & \\
\hline & Technical problems & \\
\hline & Difficulty in identifying the actual user in assessment of knowledge & \\
\hline & & \\
\hline & & \\
\hline & & \\
\hline & & \\
\hline & & \\
\hline
\end{tabular}

What is the main benefit you have gained from using Moodle?

What obstacles have you faced while using Moodle? 